\title{
Procalcitonin for the diagnosis of invasive candidiasis: what is the evidence?
}

\author{
Santi Maurizio Raineri, Andrea Cortegiani * (D, Filippo Vitale, Pasquale lozzo and Antonino Giarratano
}

\begin{abstract}
s
Procalcitonin is a widely used marker for the evaluation of infection and sepsis and to guide antibiotic therapy. During the last decade, several studies evaluated its role and diagnostic performance as a surrogate marker for the identification of Candida spp. in suspected invasive candidiasis. A low serum level and a favorable negative predictive value are the main findings for procalcitonin in this setting. The aim of this report is to provide an updated brief summary of the evidence supporting the use of PCT for the management of invasive candidiasis.
\end{abstract}

Keywords: Invasive candidiasis, Candida spp., Procalcitonin, Sepsis

We read with interest the comprehensive review by Vijayan et al. about the role of procalcitonin (PCT) as a marker of sepsis and guide for antibiotic therapy [1]. However, we believe that another important role of PCT should be emphasized in light of recent literature, namely its usefulness in suspected invasive candidiasis (IC).

IC is a frequent cause of infection and sepsis in critically ill patients and is characterized by high morbidity, mortality, and costs [2-4]. The outcome of patients with IC seems to be associated with timing of antifungal treatment initiation $[2,5]$. However, the turnaround time to the microbiological diagnosis of IC is long, ranging from 3 to 7 days [3]. Therefore, clinicians should often prescribe antifungals before definitive microbiological isolation of Candida spp. [6]. In fact, untargeted antifungal treatment is frequently used in clinical practice with high associated costs and potential risk of resistance [6]. In this regard, desirable features of a marker might be the ability to help in confirming or excluding IC when suspected and to differentiate between bacterial and fungal infection/sepsis in order to optimize antimicrobial treatment with a favorable cost-benefit balance.

In 2006, Charles et al. published a retrospective study enrolling 50 nonsurgical septic patients with positive blood cultures, 35 with bacteremia and 15

\footnotetext{
* Correspondence: cortegiania@gmail.com

Department of Biopathology and Medical Biotechnologies (DIBIMED). Section of Anesthesia, Analgesia, Intensive Care and Emergency. Policlinico P. Giaccone, University of Palermo, Via del vespro 129, 90127 Palermo, Italy
}

with candidemia [7]. They found a significantly lower PCT level in patients with candidemia (median $0.65 \mathrm{ng} /$ $\mathrm{ml}$ ) compared to those with bacteremia (median $9.75 \mathrm{ng} /$ $\mathrm{ml})$. PCT level higher than $5.5 \mathrm{ng} / \mathrm{ml}$ demonstrated a $100 \%$ negative predictive value (NPV) and $65 \%$ positive predictive value (PPV) for sepsis caused by Candida spp. Martini et al. performed a prospective study enrolling 48 critically ill surgical patients with sepsis and risk of fungal infection [8]. PCT levels were lower in patients with candidemia (median 0.71 [IQR 0.5-1.1]) than in those with bacteremia (median 12.9 [IQR 2.6-81.2]). Recently, Cortegiani et al. performed a retrospective study evaluating 260 diagnostic episodes from 182 patients $(60 \%$ surgical) [9]. The aim of this study was to assess the PCT level in septic patients with Candida, bacterial or mixed bloodstream infection (BSI) evaluated with blood culture $(\mathrm{BC})$, and a polymerase chain reaction (PCR) test. A significantly lower level of PCT was found in Candida BSI (median $0.99 \mathrm{ng} / \mathrm{ml}$ [IQR 0.86-1.34]) than in BSI caused by bacteria (median $16.7 \mathrm{ng} / \mathrm{ml}$ [IQR 7.52-50.2]) or in mixed BSI (median $4.76 \mathrm{ng} / \mathrm{ml}$ [IQR 2.98-6.08]). Consensual results were found for PCR results. A cut-off of $\leq 6.08 \mathrm{ng} / \mathrm{ml}$ for PCT yielded a sensitivity of $86.8 \%$, a specificity of $87.6 \%$, a PPV of $63.9 \%$, and a NPV of $96.3 \%$. Interestingly, more subsequent episodes of BSI were due to Candida compared to the first ones. It is known that subsequent episode of nosocomial infections is often characterized by an impaired (hypoergic) immunity and Candida spp. infections are often involved [6]. Authors speculated that this might 
have been one of the reasons explaining the lower level of PCT in patients with Candida BSI, stressing a link between the low activation of the immunity, isolation of Candida in blood, and low PCT level [9]. Very recently, Pieralli et al. performed a retrospective case-control study enrolling 64 septic patients with candidemia and 128 septic patients with bacteremia admitted in 3 internal medicine units [10]. Again, PCT levels were lower in patients with candidemia (median $0.73 \mathrm{ng} / \mathrm{ml}$ [IQR $0.26-1.85$ ]) compared to those in patients with bacteremia (median $4.48 \mathrm{ng} / \mathrm{ml}$ [IQR 1.10-18.26]). PCT higher than $2.5 \mathrm{ng} / \mathrm{ml}$ had a NPV of $98.3 \%$ with an area under the curve (AUC) of $0.76(0.68-0.84 \%)$ for identification of Candida spp. in blood. Lastly, the diagnostic performance of PCT was evaluated in association to (1-3)-beta-D-glucan (BDG), one of the widely used surrogate markers for fungal infection. Giacobbe et al. performed a retrospective study enrolling 166 patients from 3 intensive care units (ICUs), 73 with candidemia and 93 with bacteremia (almost 30\% surgical and $60 \%$ medical) [11]. Patients with candidemia had lower PCT value (median $0.76 \mathrm{vs} 4.32 \mathrm{ng} / \mathrm{ml}$ ) than those with bacteremia. Authors evaluated together the diagnostic performance of BDG and PCT using a commonly recognized cut-off value of BDG for Candida identification $(\geq 80 \mathrm{pg} / \mathrm{ml})$ and the rounded best cut-off calculated in their population for PCT in candidemia $(2 \mathrm{ng} / \mathrm{ml})$. When both markers indicated candidemia, they showed higher PPV (96\%) compared to 79 and 66\% for BDG and PCT. When both indicated bacteremia, their NPV was similar to that of BDG alone (95 vs 93\%).

Although several studies demonstrated the correlation between a low PCT level $(<2 \mathrm{ng} / \mathrm{ml})$ and Candida infection and high NPV of PCT for Candida isolation, its role in management of antifungal treatment is far from established mainly because of the limitations in study design of supporting literature. A recently published research agenda on invasive fungal infections reported the "Utilization of PCT to guide treatment initiation and duration" as one of the ten priority for future trials in the field [12]. Meanwhile, clinicians might evaluate a PCT level in an infected/ septic patient with risk factors for invasive candidiasis as one of the element to assess the probability of subsequent Candida isolation.

\section{Abbreviations}

AUC: Area under the curve; BC: Blood culture; BDG: (1-3)-beta-D-glucan; BSI: Bloodstream infection; IC: Invasive candidiasis; NPV: Negative predictive value; PCR: Polymerase chain reaction; PCT: Procalcitonin; PPV: Positive predictive value

\section{Acknowledgments}

None.

\section{Funding}

None.
Availability of data and materials

Not applicable.

\section{Authors' contributions}

SMR, AC, FV, CG, and AG conceived the content of this letter and draft the manuscript. All authors read and approved the final manuscript.

Ethics approval and consent to participate

Not applicable.

Consent for publication

Not applicable.

\section{Competing interests}

The authors declare that they have no competing interests.

\section{Publisher's Note}

Springer Nature remains neutral with regard to jurisdictional claims in published maps and institutional affiliations.

Received: 11 August 2017 Accepted: 21 September 2017

Published online: 25 September 2017

References

1. Vijayan AL, Vanimaya, Ravindran S, Saikant R, Lakshmi S, Kartik R, Mamoj G. Procalcitonin: a promising diagnostic marker for sepsis and antibiotic therapy. J Intensive Care. 2017;5:51.

2. Kullberg BJ, Arendrup MC. Invasive candidiasis. N Engl J Med. 2015;373: 1445-56.

3. Cortegiani A, Russotto V, Maggiore A, Attanasio M, Naro AR, Raineri SM, Giarratano A. Antifungal agents for preventing fungal infections in nonneutropenic critically ill patients. Cochrane Database Syst Rev. 2016;1: CD004920.

4. Cortegiani A, Russotto V, Giarratano A. Associations of antifungal treatments with prevention of fungal infection in critically ill patients without neutropenia. JAMA. 2017;317:311-2

5. Cortegiani A, Russotto V, Raineri SM, Gregoretti C, Giarratano A. Should we administer antifungal drugs before the diagnosis of invasive fungal infection in non-neutropenic critically ill patients? Turk J Anaesthesiol Reanim. 2016; 44:276-8.

6. Cortegiani A, Russotto V, Raineri SM, Gregoretti C, De Rosa FG, Giarratano A. Untargeted antifungal treatment strategies for invasive candidiasis in nonneutropenic critically ill patients: current evidence and insights. Curr Fungal Infect Rep. 2017;11:84-91.

7. Charles PE, Dalle F, Aho S, Quenot J-P, Doise J-M, Aube H, Olsson N-O, Blettery B. Serum procalcitonin measurement contribution to the early diagnosis of candidemia in critically ill patients. Intensive Care Med. 2006;32: 1577-83.

8. Martini A, Gottin L, Menestrina N, Schweiger V, Simion D, Vincent J-L. Procalcitonin levels in surgical patients at risk of candidemia. J Inf Secur. 2010;60:425-30.

9. Cortegiani A, Russotto V, Montalto F, Foresta G, Accurso G, Palmeri C, Raineri SM, Giarratano A. Procalcitonin as a marker of Candida species detection by blood culture and polymerase chain reaction in septic patients. BMC Anesthesiol. 2014;14:9.

10. Pieralli F, Corbo L, Torrigiani A, Mannini D, Antonielli E, Mancini A, Corradi F, Arena F, Moggi Pignone A, Morettini A, Nozzoli C, Rossolini GM. Usefulness of procalcitonin in differentiating Candida and bacterial blood stream infections in critically ill septic patients outside the intensive care unit. Intern Emerg Med. 2017;12:629-35.

11. Giacobbe DR, Mikulska M, Tumbarello M, Furfaro E, Spadaro M, Losito AR, Mesini A, De Pascale G, Marchese A, Bruzzone M, Pelosi P, Mussap M, Molin A, Antonelli M, Posteraro B, Sanguinetti M, Viscoli C, Del Bono V. Combined use of serum (1,3)-beta-D-glucan and procalcitonin for the early differential diagnosis between candidaemia and bacteraemia in intensive care units. Crit Care. 2017:21:176

12. Bassetti M, Garnacho-Montero J, Calandra T, Kullberg B, Dimopoulos G, Azoulay E, Chakrabarti A, Kett D, León C, Ostrosky-Zeichner L, Sanguinetti M, Timsit JF, Richardson MD, Shorr A, Cornely OA. Intensive care medicine research agenda on invasive fungal infection in critically ill patients. Intensive Care Med. 2017. 